\title{
Rainfall Trend Analysis in Context of Climate Change in Guercif City, Morocco
}

\section{Youssef Hamdach}

Professor-researcher of geography at Chouaib Doukkali University, El Jadida, Morocco

Laboratory of Space Recomposition and Sustainable Development

\begin{abstract}
The purpose of this study is to analyze the variations of rainfall events through a statistical analysis of rainfall data in Guercif station for a period of 45 years (1971-2015). The analysis of rainfall trends in Guercif station showed that global warming which we are so concerned about seem to have resulted in an increase in rainfall and not drought. Moreover, the Gumbel method has allowed us to determine return periods of rainfall. The results have shown that the rainfall is low. The annual rainfall reaches a maximum of $359 \mathrm{~mm}$ with a 100 year return period.
\end{abstract}

Keywords: Variations of rainfall, precipitation, global warming, Gumbel law, return periods

\section{Introduction:}

Climate change is one of the most complex challenges of the 21 st century. No country is immune to its effects, and no country can unilaterally make with regard to the controversial political decisions, profound technological transformations and other indivisible and far-reaching issues on a global scale (Driouech, 2010). At the same time that the planet is heating up, the precipitation regime is changing and extreme events such as droughts, floods and forest fires are becoming more frequent (Lamine et al. 2016 ; Hanchane, 2014).

The present study consists of analyzing the variations of rainfall events through a statistical analysis of the rainfall data of the station of Guercif for a chronicle of 45 years (1971-2015). The main objective is to extract all the information that can inform us about the rainfall characteristics of this period, to determine the rainfall trends, to extract the rainfall variability and to determine the periods of return of extreme rainfall. 


\section{Study area}

The province of Guercif, which is part of the Oriental Region, is located to the east of the Province of Taza, west of Taourirt, south of Driouch and Nador and north of Missour (fig.1).

The province of Guercif covers an area of $7310 \mathrm{Km}^{2}$. It has a very varied relief marked mainly by three major components: the Rifmountains range and the pre-Rif hills in the North, the Middle Atlas mountain chain in the South and the Guercif plain in the centre. Two large wadis cross the region, namely: OuedMelelou and OuedMoulouya. Vegetal cover consists mainly of alfa, green oak, cedar, reforestation and secondary species.

According to general census of the population and the habitatof 2014, the population of the province is estimated at 216717 inhabitants. The main agricultural activity of the province of Guercif is the exploitation of the olives. This sector is undergoing considerable development as it is the fundamental resource of farmers. At the same time, this activity includes cattle breeding, barley and wheat farming, and vegetables.

\section{Methodology}

To define precisely the statistical characteristics of the chronicle studied (1971-2015) of the station Guercif, we will apply a series of statistical tests (Layan, 2012; El Ghachi, 2015) to identify the various extreme situations that the city experienced during this chronicle, Thus extracting all the information that can inform us about the climatic characteristics of this period (Theobald et al, 2016). The precipitation data recorded at the Guercif station at the annual, monthly, seasonal and daily levels were treated by Excel to extract the various representative graphs and analyze them thereafter (Theobald et al., 2016). Thus, we have carried out a frequency analysis of annual and daily rainfall (Driouech, 2010; Patade et al. 2016), a calculation of the return periods (François,1993; patade et al., 2016), a rainy season extraction and we also determined the exceptional rains (Zaheed et al., 2014). 

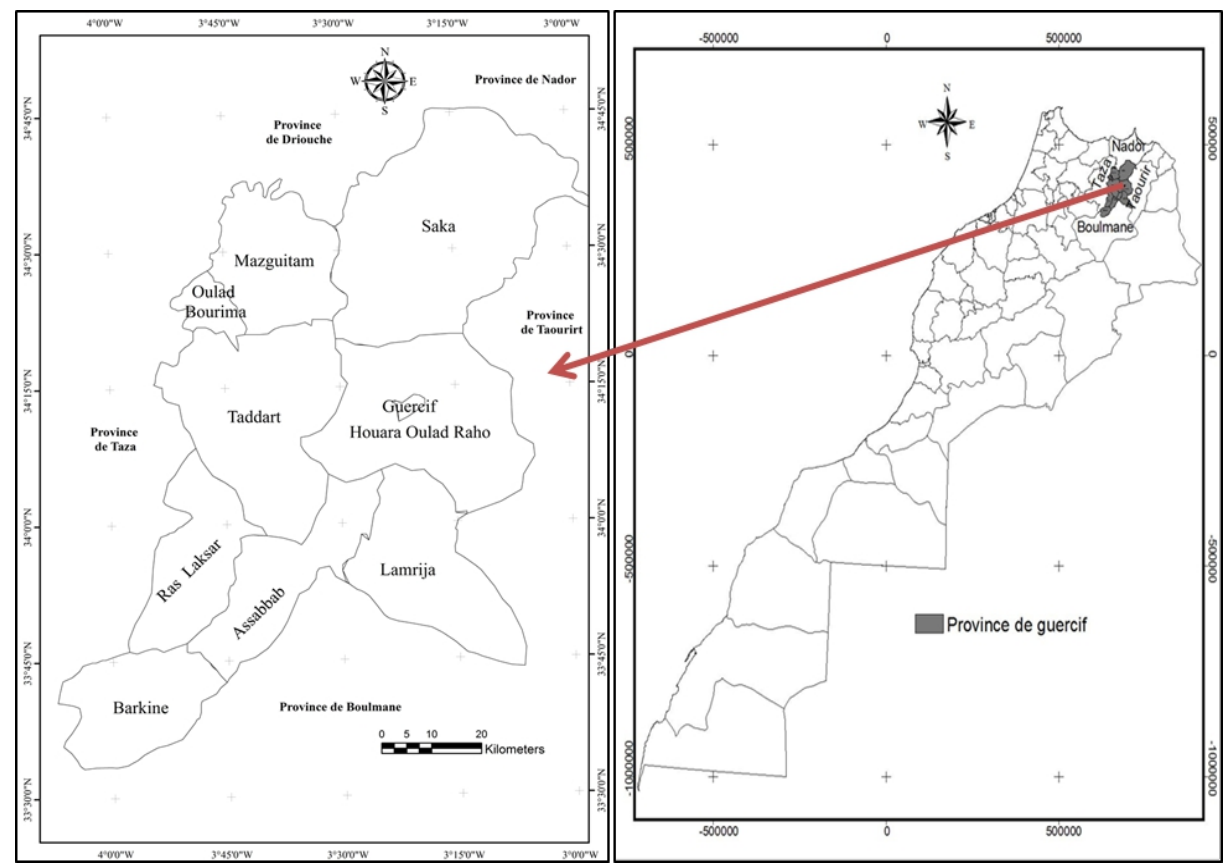

Location of Guercif City in the province of Guercif

Location of province de Guercif in Morocco

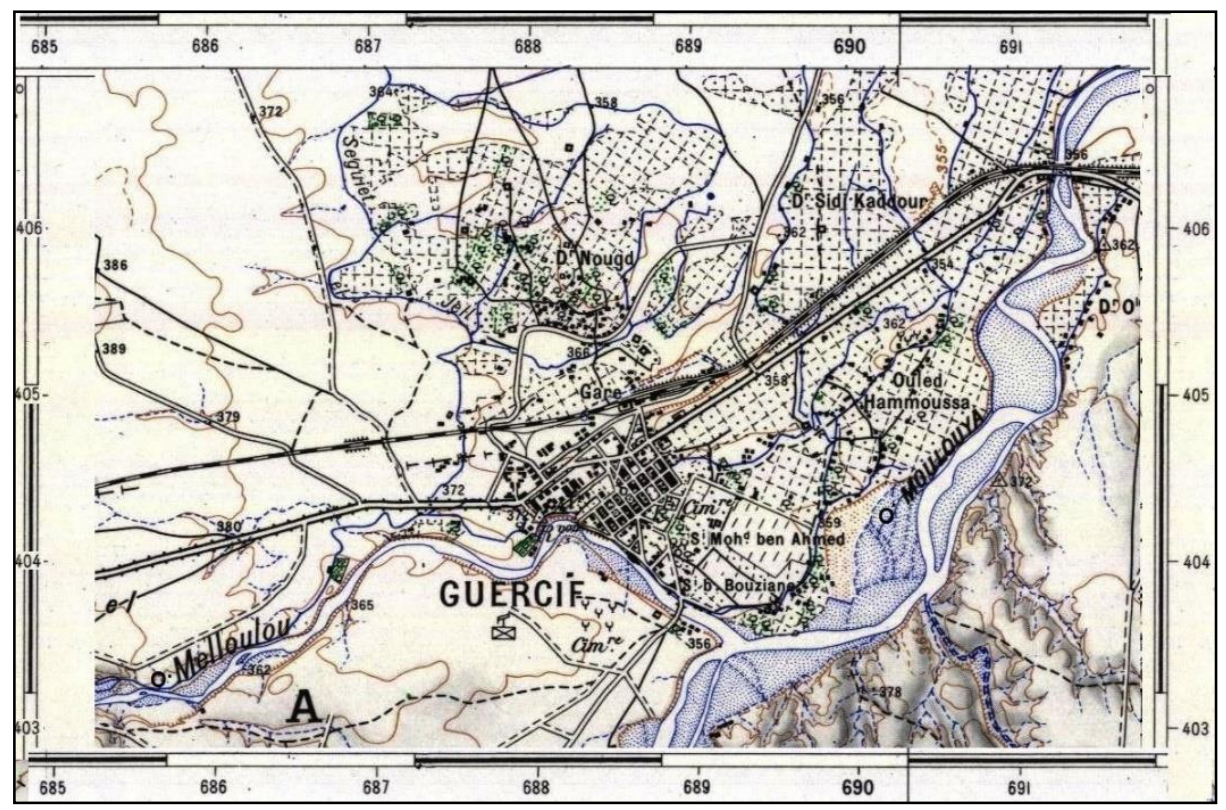

Guercif city (topographic map)

Figure 1: Location of Guercif city at the National and regional level 


\section{Results and discussion}

\section{Development of annual rainfall characteristics}

The mean annual rainfall is about $164 \mathrm{~mm}$ in the Guercif station, ranging from $66 \mathrm{~mm}$ in 1983 (extremely dry years) to $359 \mathrm{~mm}$ in 1976 (relatively rainy years). Interannual variability Of the precipitations have a high variability: the difference between the maximum and the minimum is $293 \mathrm{~mm}$ (Fig. 2).

The analysis shows that the maximum rainfall amounts are observed in the years 2007, 1975, 1976, 1973 and 2000 (Fig. 3). The maximum of these rainfall values reached the $200 \mathrm{~mm}$ recorded in 2007 .

The analysis in Figure 2 also indicates an upward trend in annual precipitation with an increase of about $30 \mathrm{~mm}$ in 45 years, i.e. $0.66 \mathrm{~mm}$ per year.

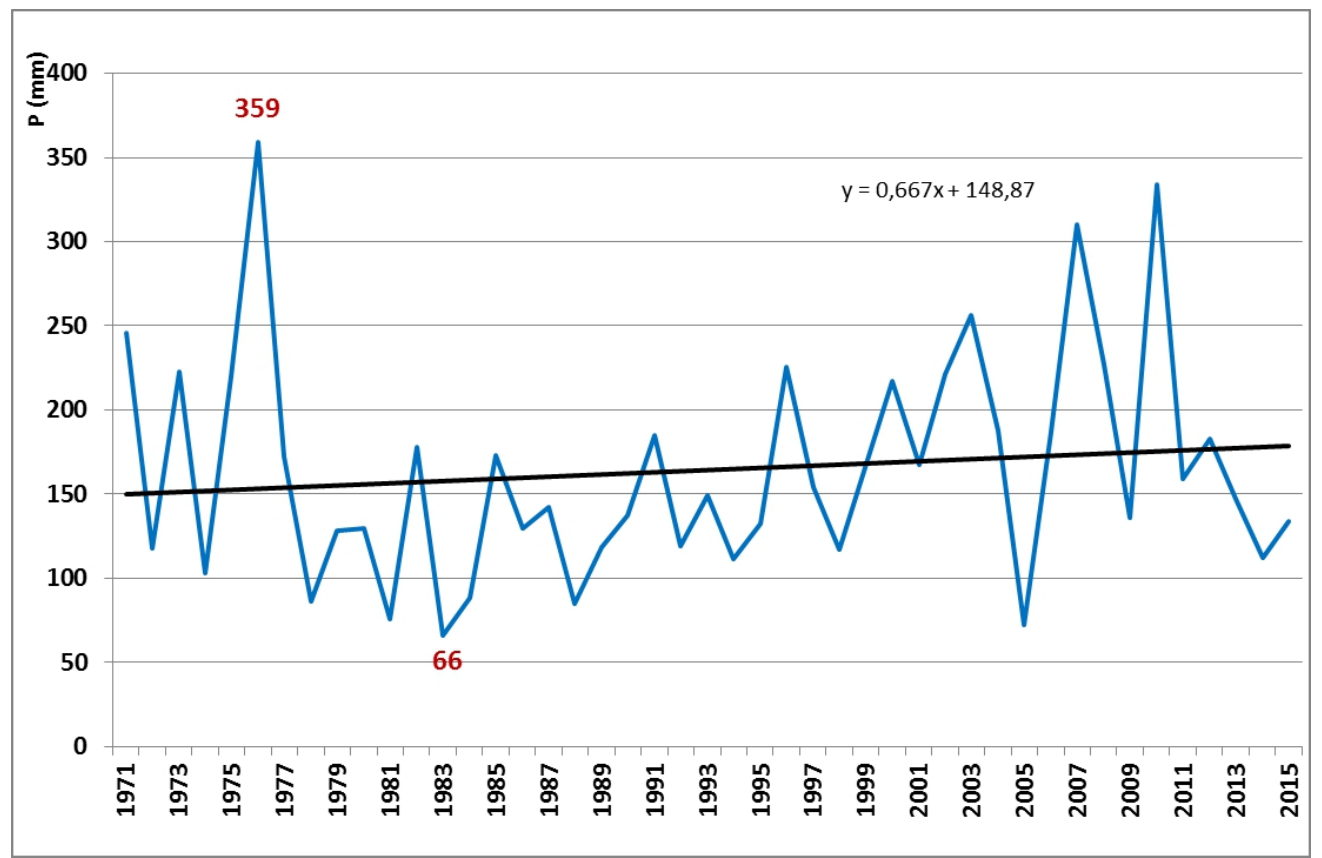

Figure 2: Annual precipitation of the Guercif station compared to the average (1971-2015)

\section{Frequency analysis of the annual precipitation of the Guercif station} (1971-2015)

Frequency analysis is a statistical method of prediction consisting in studying past events, characteristics of a given process (climatic or other), in order to define the probabilities of future occurrence (El Ghachi, 2015).

To detect the distribution of the annual rainfall heights for the period (1971-2015), we tried a frequency analysis by testing several laws. After several tests, it is the Gumbel law that is most adapted to the annual precipitation of the station of Guercif. The distribution function of the Gumbel law is represented by the equation: 


$$
\mathrm{F}(\mathrm{x})=\exp \left[-\exp \left(-\frac{\mathrm{x}-\mathrm{a}}{\mathrm{b}}\right)\right]
$$

With the following reduced variable $\mathrm{u}=\mathrm{x}=\frac{\mathrm{x}-\mathrm{a}}{\mathrm{b}}$

Where $\boldsymbol{a}$ and $\boldsymbol{b}$ are the parameters of the Gumbel model. $(\mathrm{f}(\mathrm{x}))]$

In a graph of Gumbel the distribution is written as follows: $\mathrm{u}=-\ln [-\ln$

Practically, the probability of the values of an observed sample is illustrated by the formula of HASEN:

$$
\frac{r-0,5}{n}
$$

Where $\boldsymbol{r}$ is the rank in the data series ranked by increasing values, $\boldsymbol{n}$ is the sample size.

In this study, the annual rainfall of the Guercif station was adjusted for a series of rather long observations (45 years) by the Gumbel law, this adjustment allowed to estimate the precipitation values for different return frequencies (Fig. 3).

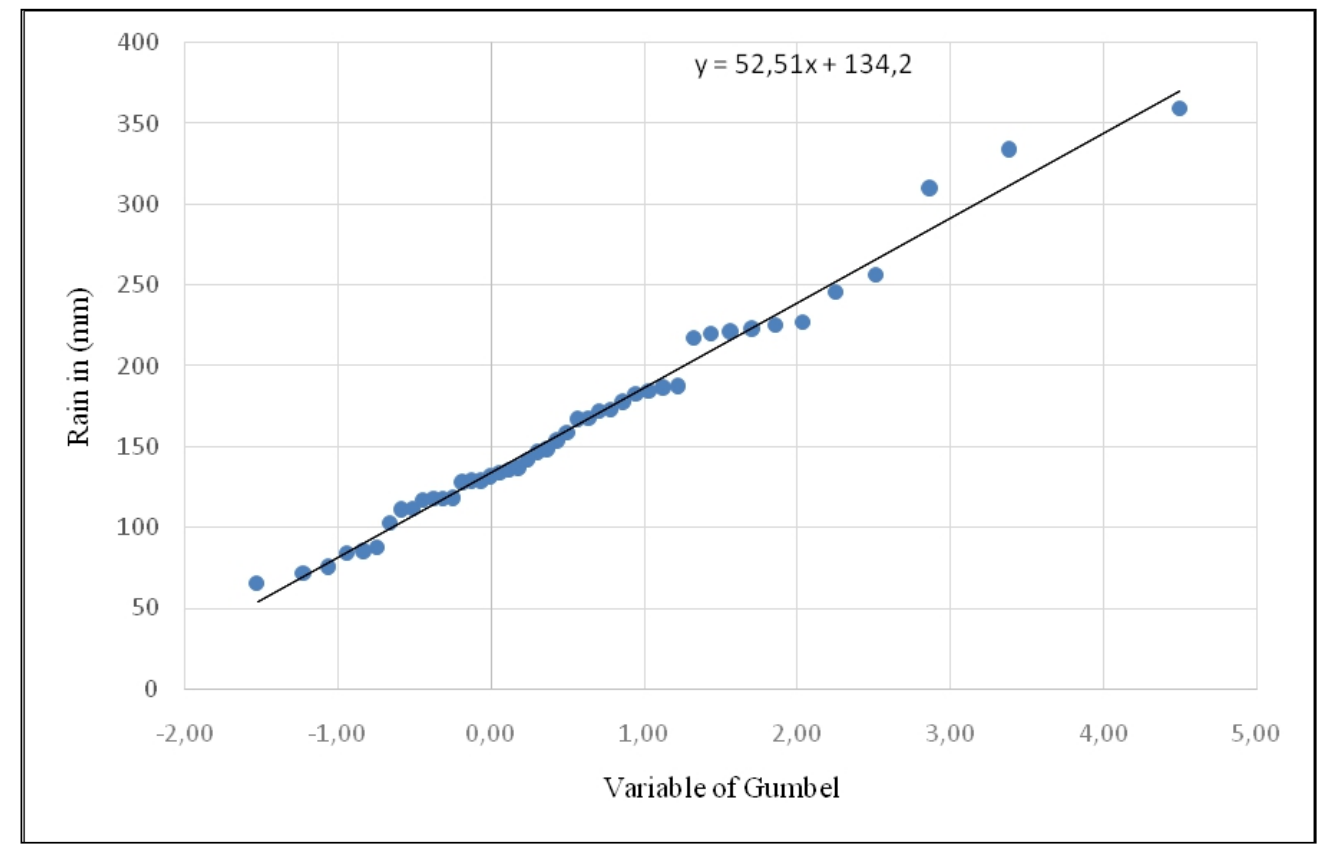

Figure 3: Statistical adjustment of Guercif's precipitation to Gumbel's law.

According to (table1) the values obtained, we notice that the average of the period 1971-2015 $(164 \mathrm{~mm})$ corresponds to a frequency $1 / 2$. The lowest value of the chronicle $(66,1983)$ corresponds to a frequency of $1 / 100$. The maximum value $(359 \mathrm{~mm}, 1976)$ corresponds to a frequency of $1 / 100$. 
Table 1: return periods for precipitation from the Guercif station according to the Gumbel law (1971-2015)

\begin{tabular}{|c|c|c|c|c|c|c|c|c|c|c|c|}
\hline & \multicolumn{5}{|c|}{ Towards dry } & & \multicolumn{5}{|c|}{ Towards the humid } \\
\hline Frequency & $1 / 100$ & $1 / 50$ & $1 / 20$ & $1 / 10$ & $1 / 5$ & $1 / 2$ & $1 / 5$ & $1 / 10$ & $1 / 20$ & $1 / 50$ & $1 / 100$ \\
\hline $\begin{array}{l}\text { Return } \\
\text { periods }\end{array}$ & $\begin{array}{c}100 \\
\text { years }\end{array}$ & $\begin{array}{c}50 \\
\text { years }\end{array}$ & $\begin{array}{c}20 \\
\text { years }\end{array}$ & $\begin{array}{c}10 \\
\text { years }\end{array}$ & $\begin{array}{c}5 \\
\text { years }\end{array}$ & $\begin{array}{c}2 \\
\text { years }\end{array}$ & $\begin{array}{c}5 \\
\text { years }\end{array}$ & $\begin{array}{c}10 \\
\text { years }\end{array}$ & $\begin{array}{c}20 \\
\text { years }\end{array}$ & $\begin{array}{c}50 \\
\text { years }\end{array}$ & $\begin{array}{c}100 \\
\text { years }\end{array}$ \\
\hline $\begin{array}{l}\text { Precipitation } \\
\text { in } \mathbf{~ m m}\end{array}$ & 66 & 72 & 76 & 86 & 117 & 164 & 222 & 246 & 310 & 334 & 359 \\
\hline
\end{tabular}

\section{The rainfall regime at the station of Guercif (1971 - 2015)}

The analysis of the data of the average monthly rainfall regimes during the period 1971 -2015 shows that the Guercif station has an (Autumn, Spring, Winter, Summer) regime (Fig. 4).

The autumn at the Guercif station is the rainiest season then comes the spring season and the winter season. Summer also records a significant value (15 $\mathrm{mm}$ ) mainly related to thunderstorms. The precipitation is presented throughout the year, which explains the flooding character of the city of Guercif even during the summer period

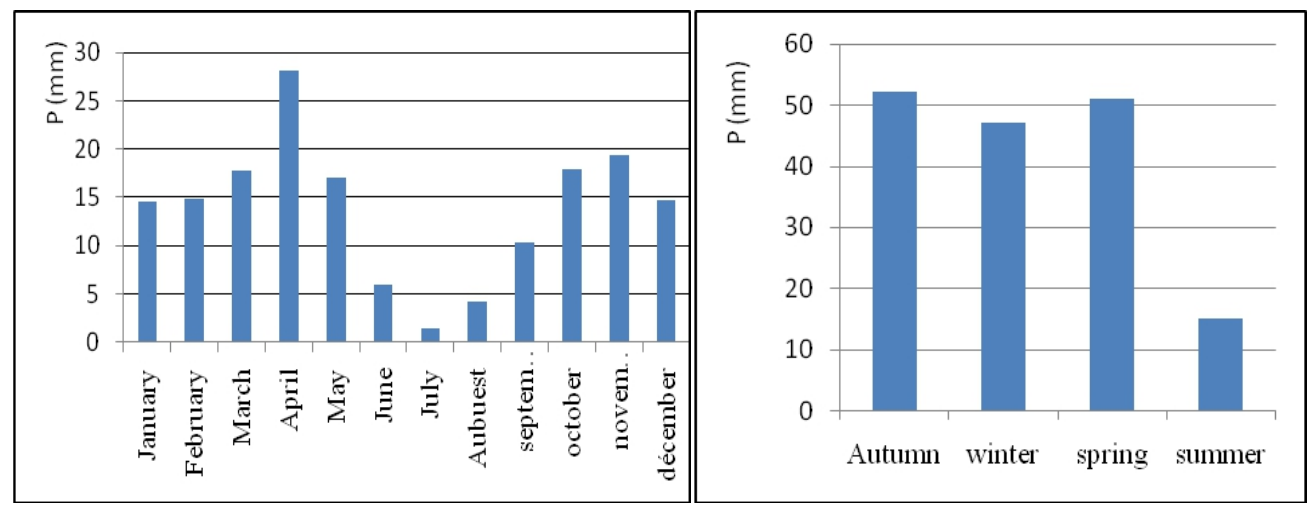

Figure 4: Monthly and seasonal precipitation average at the station of Guercif (1071-2015)

Identification of maximum heights of monthly precipitation at the Guercif station (1971-2015)

The deviation between the maximum and the minimum of the precipitations is $185.2 \mathrm{~mm}$, which clearly shows the rainfall contrast between winter and summer (Fig. 5). What is surprising isthe summer period, which recorded very interesting values (61 mm in June 1996 and $41 \mathrm{~mm}$ in August 2010). These precipitations were mainly due to the storm phenomenon that the city experienced during the period. 


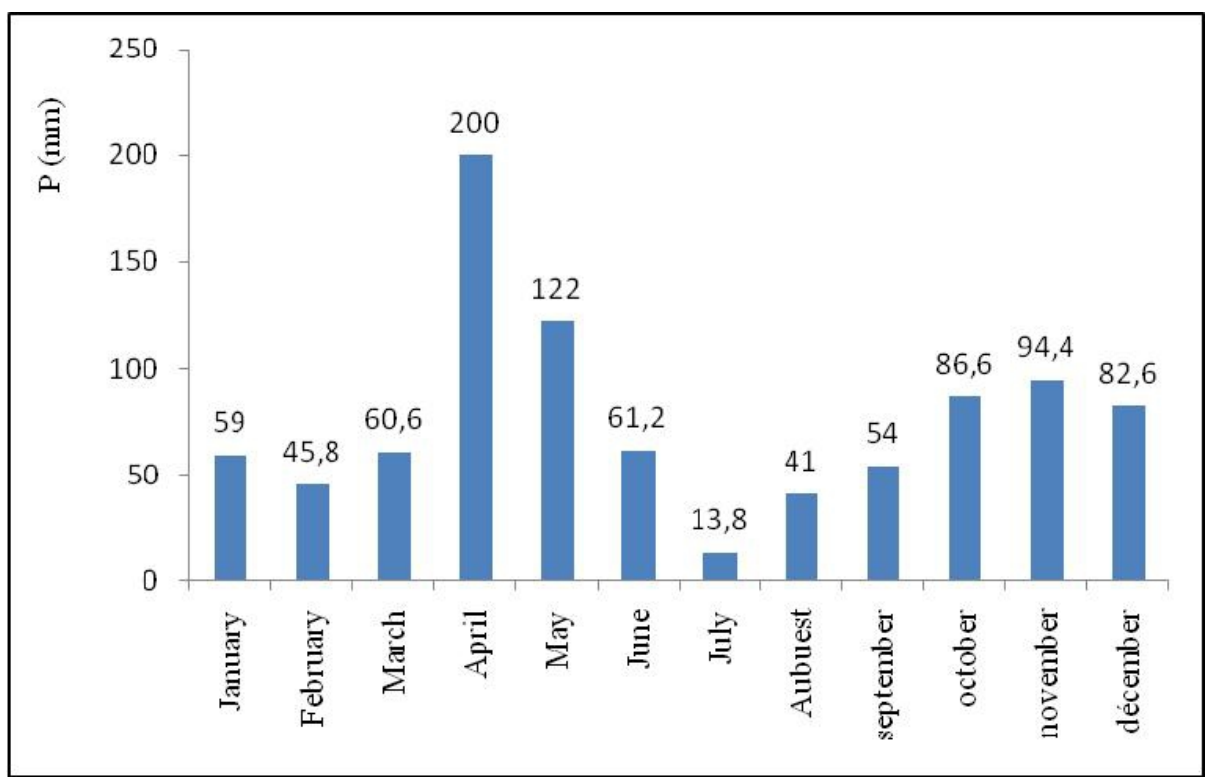

Figure 5: Monthly precipitation maxima of the Guercif station (1971-2015)

\section{Extraction of rainy days in the station Guercif (1980-2015)}

According to Figure 6, the number of rainy days differs from year to year (wet and dry years). This number rises to 93 days in 1980 (wet years), compared to a decrease of 18 days in 2000 (dry year).

It is clear that the variation of these rainy days shows the probability of the appearance of flooding phenomena. From a statistical point of view, of the 35 years, 420 months studied, only $10 \%$ of the days are rainy (1216 days).

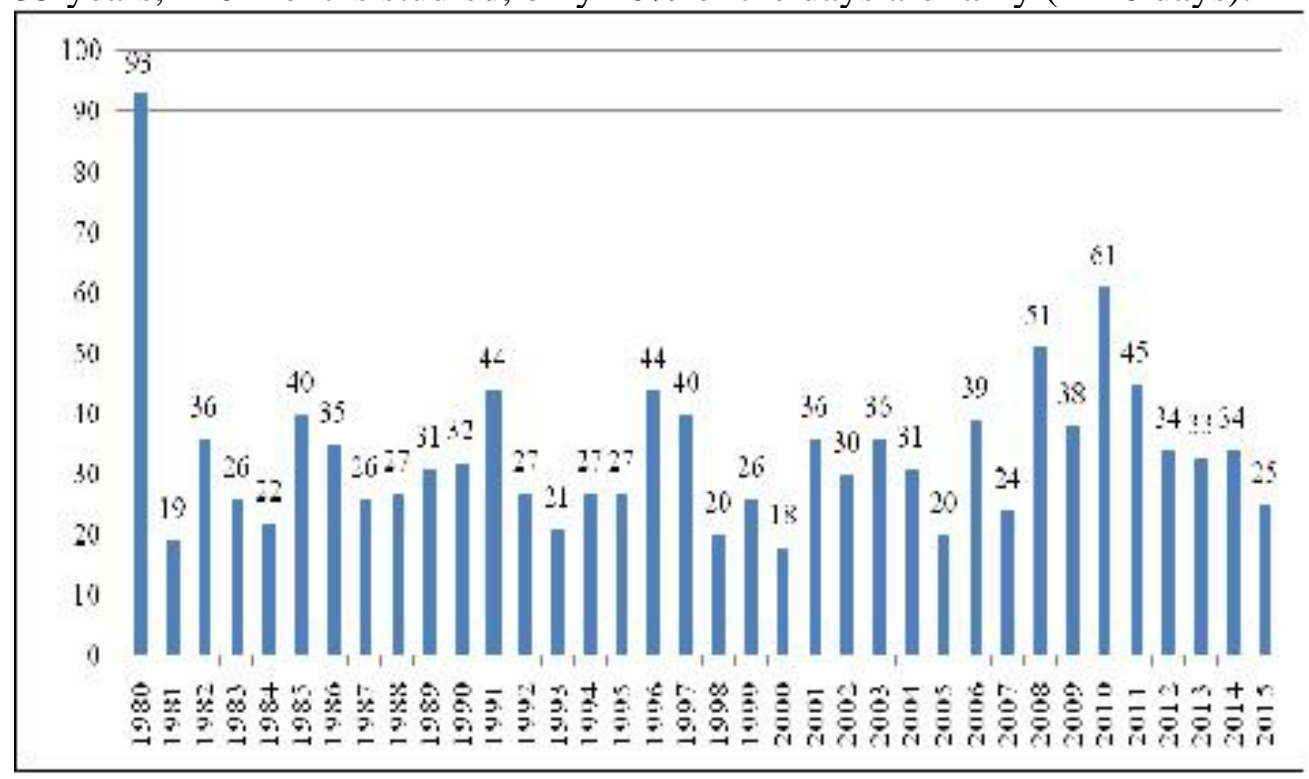

Figure 6: Extraction of rainy days at the annual scale, Guercif station (1980-2015) 


\section{Conclusion}

The climate study is of great importance because it allows characterising the climate of the region of Guercif with these temporal variations. The present study examined widely the deviation that can occur between a wet year and a dry year. At the seasonal level, the field of study receives rainfall throughout the year; autumn is the rainiest season then comes the spring and the winter season.

The analysis of the trend curves of the station of Guercif showed that the global warming of which we are concerned at present seems to be translated to the station of Guercif by an increase of precipitations and not by a drought.

\section{References:}

1. Driouech F. (2010). Distribution des précipitations hivernales sur le Maroc dans le cadre d'un changement climatique : descente d'échelle et incertitudes. Thèse de doctorat. INP-Toulouse, 163p.

2. El Ghachi M., \& Morchid F.Z., (2015). Analyse des tendances pluviométriques dans la ville de Khénifra dans un contexte de variabilité climatique. J. Mater. Environ. Sci. 6 (11), pp 3346-3358.

3. François D., Gille E., \& Zumstein J.F.1993. L'eau, la terre et les hommes. P.U. Nancy, pp 137-146.

4. Hanchane M. (2014). Impact du changement climatique sur les précipitations au Maroc: de la modélisation prospective à l'observation des séries temporelles actuelles. Cas de Taza et Berkine. Revue Taza : Espace, société et histoire, $N^{\circ}$ 1, pp 95-118.

5. Lamine D., Ansoumana B., Dior D. (2016). Spatiotemporal Trend Analysis of the Mean Annual Rainfall in Senegal. European Scientific Journal April, vol.12, No.12, pp 231 - 245

6. Layan B., Dridri A., Benaabidate L., \& Zemzami M. (2012). Détermination des crues de projet par les aspects du débit de pointe et de l'hydrogramme de crue au niveau de la commune ain boukellal, bassin versant de l'oued larbaa, maroc. European Scientific Journal December edition vol.8, No.29, pp 209-220.

7. Patade S., Shete S., Malap N., \& Kulkarni G., (2016). Observational and simulated cloud microphysical features of rain formation in the mixed phase clouds observed during CAIPEEX. Atmospheric Research,169, Part A, pp 32-45

8. Retalis A., Katsanos A., \&Michaelides S., (2016). Precipitation climatology over the Mediterranean Basin — Validation over Cyprus. Atmospheric Research, 169, Part B, pp 449-458

9. Theobald A., McGowan H., \& Speirs J., (2016). Trends in synoptic circulation and precipitation in the Snowy Mountains region, 
Australia, in the period 1958-2012. Atmospheric Research, 169, Part B, pp. 434-448.

10. Zaheed H., Sabiha A., Mamunul I., (2014). Climate change and trend of rainfall in the South-East Part of Coastal Bangladesh. European Scientific Journal, vol.10, No.2, pp 25-39 